Saka et al., Afr J Tradit Complement Altern Med., (2017) 14 (6): 20-26

https://doi.org/10.21010/ajtcam.v14i6.3

\title{
ANTI-DIABETIC AND ANTIOXIDANT POTENTIALS OF AQUEOUS EXTRACT OF EUCALYPTUS GLOBULUS IN EXPERIMENTALLY-INDUCED DIABETIC RATS
}

\author{
Saka W.A ${ }^{1}$, Akhigbe R.E ${ }^{1,2^{*}}$, Ajayi A.F ${ }^{1}$, Ajayi L.O ${ }^{3}$, Nwabuzor O.E ${ }^{1}$ \\ ${ }^{1}$ Department of Physiology, Ladoke Akintola University of Technology, Ogbomoso, Oyo state, Nigeria. \\ ${ }^{2}$ State Specialist Hospital, Osogbo, Osun State. ${ }^{3}$ Department of Biochemistry, Lagos State University \\ College of Medicine, Lagos state, Nigeria.
}

*Corresponding Author E-mail: akhigberoland@gmail.com

\begin{tabular}{|l|}
\hline \multicolumn{1}{c|}{ Article History } \\
Received: $17,09.2016$ \\
Revised Received: $28,01.2017$ \\
Accepted: $31,01.2017$ \\
Published Online: $15,11.2017$ \\
\hline
\end{tabular}

\begin{abstract}
Background: Evaluation of the medicinal uses of plants remains a growing field of research. This study investigated the effects of Eucalyptus globules on alloxan -induced diabetic rats.

Materials and Methods: Thirty male albino rats were randomized into 5 groups $(n=6)$. Group A served as the control and was maintained on standard rat chow and water ad'libitum. Diabetes was induced in Group C, D and E animals by intraperitoneal administration of alloxan monohydrate $(150 \mathrm{mg} / \mathrm{kg})$. Groups B and D were orally administered with aqueous extract of Eucalyptus globulus at a dose of $150 \mathrm{mg} / \mathrm{kg}$ per oral daily for 4 weeks, while group E received glibenclamide at a dose of $0.6 \mathrm{mg} / \mathrm{kg}$ orally in addition. Fasting plasma glucose, antioxidant status (catalase and xanthine), malondialdehyde (MDA), liver function enzymes (AST and ALT) and bicarbonate ion $\left(\mathrm{HCO}_{3}{ }^{-}\right)$were assessed after 4 weeks.

Results: Aqueous extract of Eucalyptus globulus leaves significantly reduced fasting plasma glucose level, MDA, $\mathrm{HCO}_{3}{ }^{-}$, and liver enzymes $(P<0.05)$. The aqueous extract also increased serum levels of xantine oxidase and catalase significantly $(P<0.05)$. The effects of the aqueous extract on diabetic rats were similar to those of glibenclamide. Conclusion: Findings from this study revealed that aqueous extract of Eucalyptus globulus has hypoglycaemic property. The botanical also prevents complication of diabetes such as lipid peroxidation and ketoacidosis via its antioxidant potentials. This study lends credence to the ethnomedical use of the botanical in the management of diabetes.
\end{abstract}

Key words: $\quad$ Eucalyptus globulus, diabetes, lipid peroxidation, ketoacidosis, Ethnomedicine, liver enzymes

\section{Introduction}

Eucalyptus globules belongs to the family of Myrtaceae (Akin and Aktumsek, 2010). It is an ever-green fast growing plant commonly found in South-east Australia and Tasmania (Arise et al., 2009). It is the commonest eucalypts (Damjanović-Vratnicaet al., 2011), and also found in other countries including Nigeria. It is a useful raw material in the pulp industry. The eucalyptus oil (Oleum eucalypti) it produces makes it useful in aroma- and phytotherapy (Buchbauer, 2000; Bremness, 2004; Emara and Shalaby, 2011; Chalchat et al., 2001).

Eucalyptus globules leaves contain cineol, rutin, terpineol, sesquiterpene, alcohols, aliphatic aldehydes, isoamyl alcohol, ethanol, terpenes, tanins (Duke, 1985; Eidi et al., 2009), and manganese (Pinto et al., 2007). The oil from the botanical has been of interest due to its biological activities (Damjanović-Vratnicaet al., 2011).

Diabetes mellitus is a clinical condition characterize by high level of plasma glucose due to absolute or relative insulin deficiency (Shobacket al., 2011). There are different types of diabetes mellitus which include the type I and II, and gestational diabetes; diabetes has however been associated with genetic predisposition, infections, endocrinopathies and drugs. (Risérus and Willet, 2009).

Oxidative stress is caused by an imbalance between the production of oxidants and antioxidant with consequent generation of excess reactive oxygen species (ROS) which damages molecular targets (Martin et al.1996; Berlett and Standtman, 1997; Finkel and Halbroook, 2000; Pietta, 2000; Akhigbe, 2014). On the other hand metabolic acidosis is a state of by excessive acid production, reduced acid excretion, or reduced consumption or loss of body alkali (Hamblin et al., 1989). 
Some studies have documented the antihyperglycemic and anti hyperlipidemic effects of Eucalyptus globulus (Gray and Flatt, 1998). However, no report has documented the effect of the extract on the complications associated with diabetes such as ketoacidosis.

This study thus evaluated the effect of aqueous extract of Eucalyptus globulus leaves on alloxan-induced diabetes and its attendant complications. The possible mechanism of action of the botanical was also evaluated.

\section{Materials and Methods \\ Experimental Animals}

Thirty normoglycaemic male albino rats were used for the study. The animals were of comparable age and weight. They were acclimatized for 4 weeks at the animal house of the Department of Physiology, LAUTECH before been used for the study.

\section{Housing Protocol}

The animals were housed in cages and allowed free access to water and standard grower's marsh poultry diet throughout the experimental procedure. All albino rats received humane care as outlined in the guidelines for the care and use of laboratory animals for experimentation.

\section{Extract Preparation}

Fresh Eucalyptus globulus leaves were obtained from the Eucalyptus tree planted in the University. A voucher specimen authentication of the plant was obtained at the LAUTECH Herbarium in the department of pure and applied biology.

The leaves were sundried and homogenized to a fine powdered form and then percolated in 1000ml of distilled water (a suspension of $100 \mathrm{~g}$ of Eucalyptus globulus leaves powder in $1000 \mathrm{ml}$ of distilled water for about 21 hours) (Ismail, 2008).Two methodological procedures were adopted in the aqueous extraction of Eucalyptus globulus leaves. They were filtration and steam distillation.

\section{Filtration Technique}

After 21 hours of suspension of 100g of Eucalyptus leaves powder in 1000ml of distilled water, the resulting mixture was then filtered. The filtration process was performed in a fume cupboard. A vacuum pump was used and consists of a Buchner flask and Buchner funnel of which the Whatman filter paper is placed. Filtration of the resulting mixture of Eucalyptus globulus leaves was aided by the help of the vacuum pump. At the end of the filtration process, the solid residue was left behind in the Buchner funnel and the filtered fluid was left in the Buchner flask.

\section{Steam Distillation Technique}

The resulting fluid extract or filtrate in the flat bottomed Buchner flask was then subjected to steam distillation. The steam distillation process was carried out by placing the Buchner flask containing the fluid extract or filtrate the heating mantle acting as a rotatory evaporator. The heating mantle was regulated at a temperature of $100^{\circ} \mathrm{C}$ due to the use of distilled water as the solvent of extraction. At the end of the overall evaporation process, the resulting extract obtained was in a semi solid form (ie. $160.2 \mathrm{ml}$ ).

\section{Animal Treatment}

The animals were randomly grouped into five. Each group had 6 rats.

Group A: This group of animals served as the control. They were on grower's marsh diet and distilled water ad libitum throughout the study.

Group B: This group of animals served as treated control group and were administered aqueous extract of Eucalyptus globulus leaves at a dose of $150 \mathrm{mg} / \mathrm{kg}$ orally for 4 weeks.

Group C: This group of animals served as the untreated diabetic group.

Group D: They were orally administered with aqueous extract of Eucalyptus globulus at a dose of $150 \mathrm{mg} / \mathrm{kg}$ orally daily for 4 weeks.

Group E: They were orally administered glibenclamide at a dose of $0.6 \mathrm{mg} / \mathrm{kg}$ orally daily for 4 weeks.

\section{Induction of Diabetes}

Diabetes was experimentally induced by intraperitoneal administration of alloxan monohydrate $5 \% \mathrm{w} / \mathrm{v}$ at a dose of $150 \mathrm{mg} / \mathrm{kg}$. Blood glucose was checked after 48 hours of administration of alloxan and rats with blood glucose greater than $200 \mathrm{mg} / \mathrm{dl}$ were considered diabetic and used for the experimental study. 


\section{Biochemical assay}

During the course of study, blood glucose level was examined by the collection of blood samples via the tail in 12-hour overnight fasted animals. The blood glucose level was determined by the use of accu-check glucose assay kit.

Blood was collected from the apex beat of the heart after the dissection of animals to expose the heart. The blood samples were first collected into EDTA sample bottle and then the blood was spinned in a centrifuge machine to separate the plasma (supernatant) from the serum. The plasma collected was used to assay for the level of activity of alanine aminotransferase and aspartate aminotransferase using standard kits according to the manusfacturer's guideline.

\section{Tissue Homogenization}

The livers were removed and rinsed with KCL (potassium chloride 1.15\%) to blood. The total weight of the liver was examined on the electronic weighing balance before being sliced into small pieces. The liver fragments were then homogenized in equal volume of 10mM Tris/HCL buffer, $\mathrm{pH} 7.4$ and $0.25 \mathrm{M}$ sucrose solution in a ceramic mortar and pestle, after which oxidative stress, Lipid peroxidation, antioxidant status, liver function enzymes and metabolic acidosis were determined by the method previously documented (Saka et al., 2011; Ige et al., 2011; Ajayi and Akhigbe, 2012).

\section{Statistical Analysis}

Data were analyzed using one-way analysis of variance. Bon ferroni test was used as post hoc test. Data are presented as mean \pm standard error of the mean (SEM). Analyses were done using Graph Pad Prism software. The level of significance was set at $P<0.05$.

\section{Results}

Blood glucose of Group B animals significantly increased $(P<0.05)$ when compared to Group A while blood glucose of Group D animals significantly reduced $(\mathrm{P}<0.05)$ when compared to Group $\mathrm{C}$ animals. The antioxidant status of Group B animals and Group D animals also significantly increased $(\mathrm{P}<0.05)$ when compared to Group A and Group C. There was a non-significant reduction (P>0.05) in MDA (malondialdehyde) of Group B animals and Group D animals when compared with Group A and Group $\mathrm{C}$ animals. There was a significant reduction in AST, ALT and $\mathrm{HCO}_{3}{ }^{-}$of Group B and Group D animals when compared with the Group A and Group C animals.

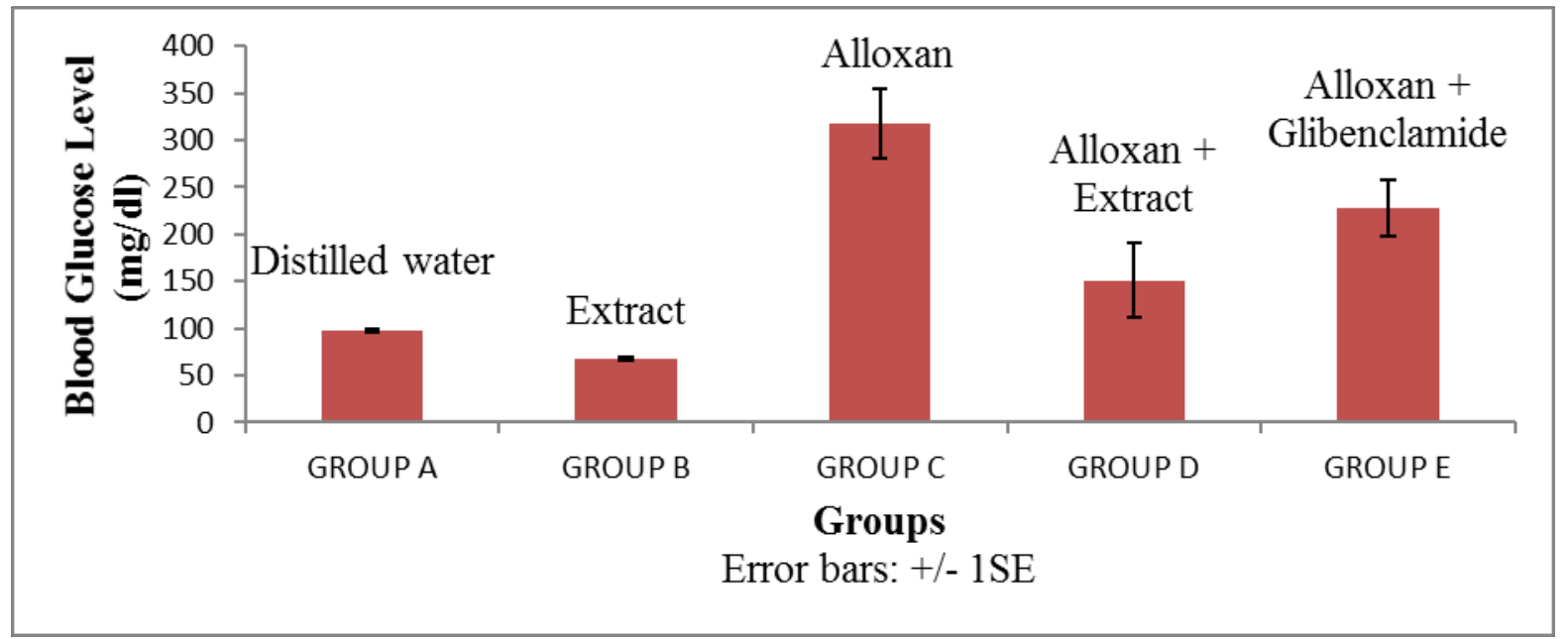

Figure 1: Effect of Eucalyptus Globulus Extract on Blood Glucose Level 


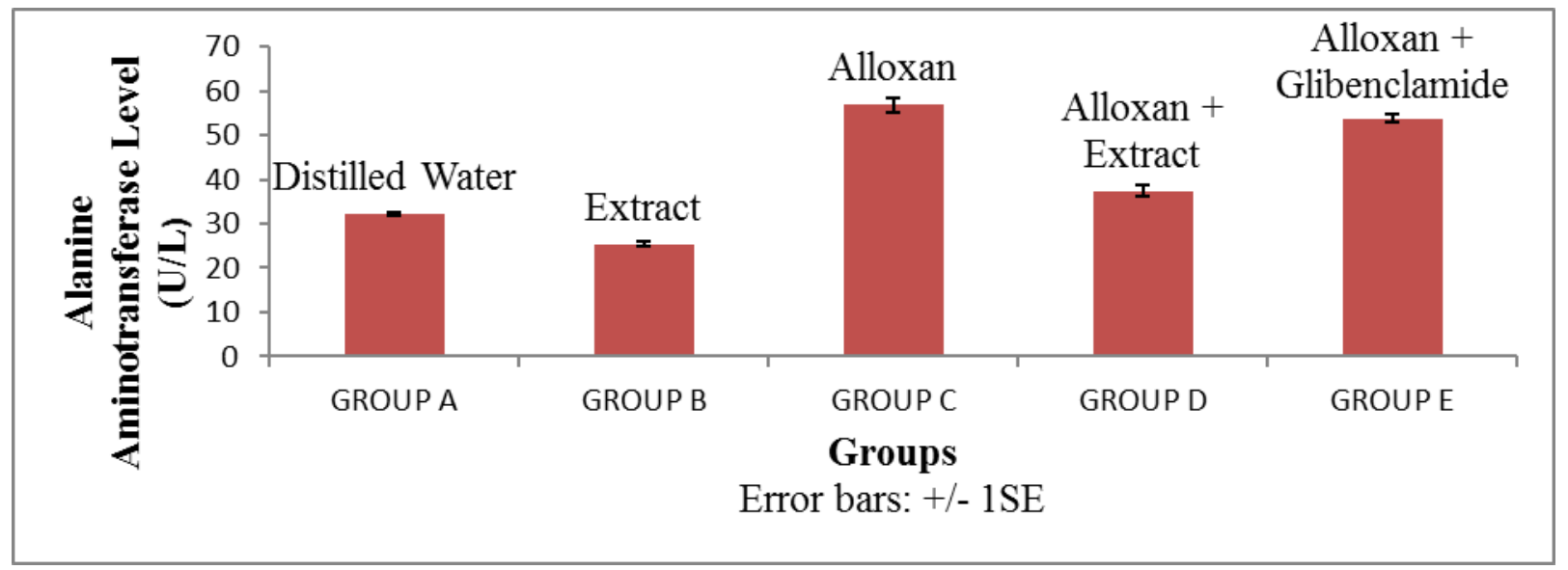

Figure 2: Effect of Eucalyptus Globulus Extract on Alanine Aminotransferase Level

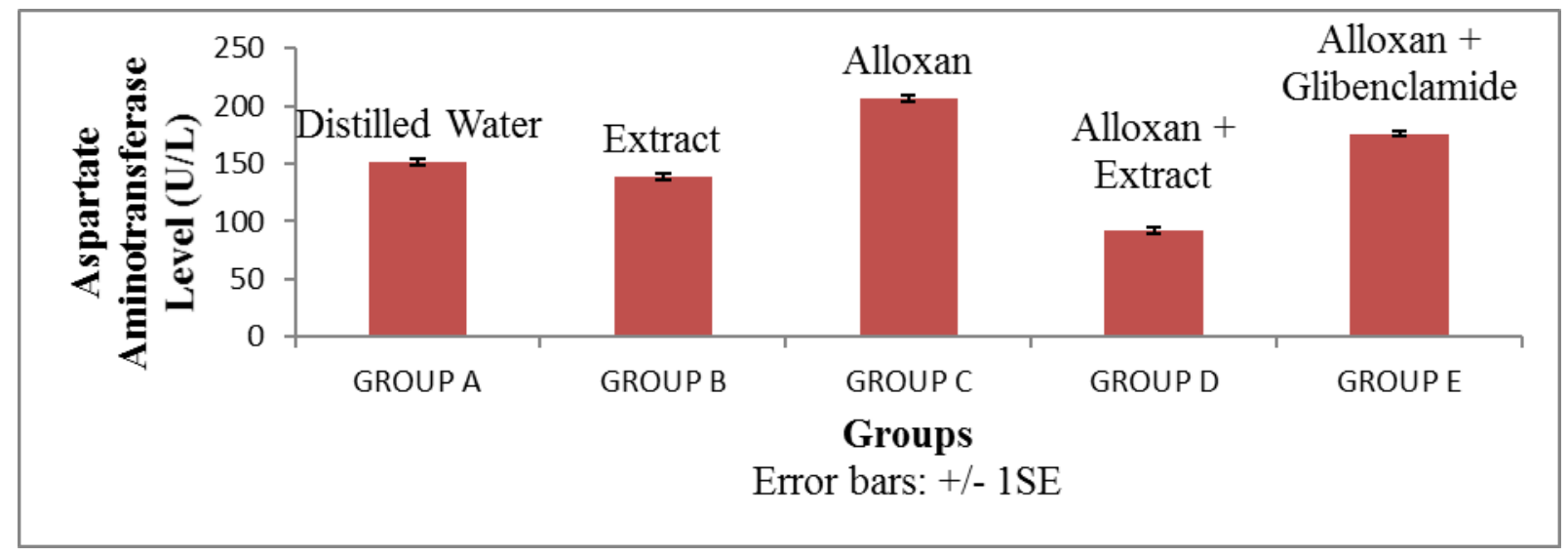

Figure 3: Effect of Eucalyptus Globulus Extract on Aspartate Aminotransferase Level

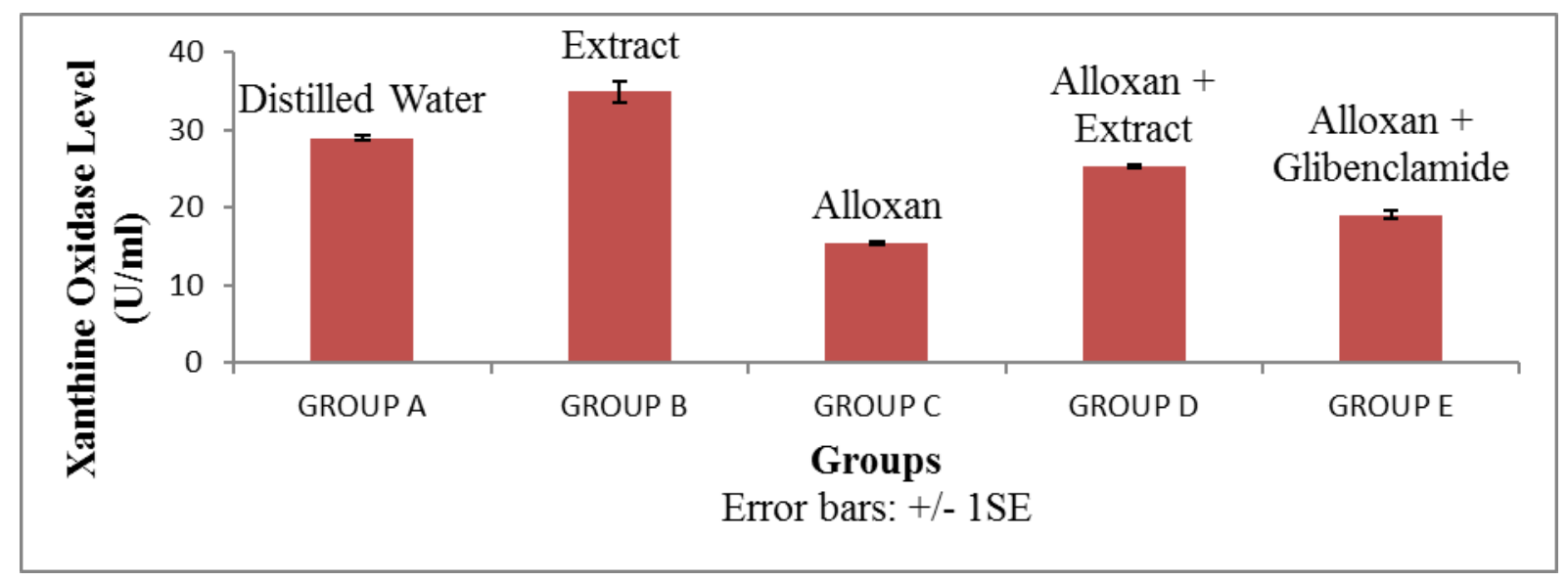

Figure 4: Effect of Eucalyptus Globulus Extract on Xanthine Oxidase Level 


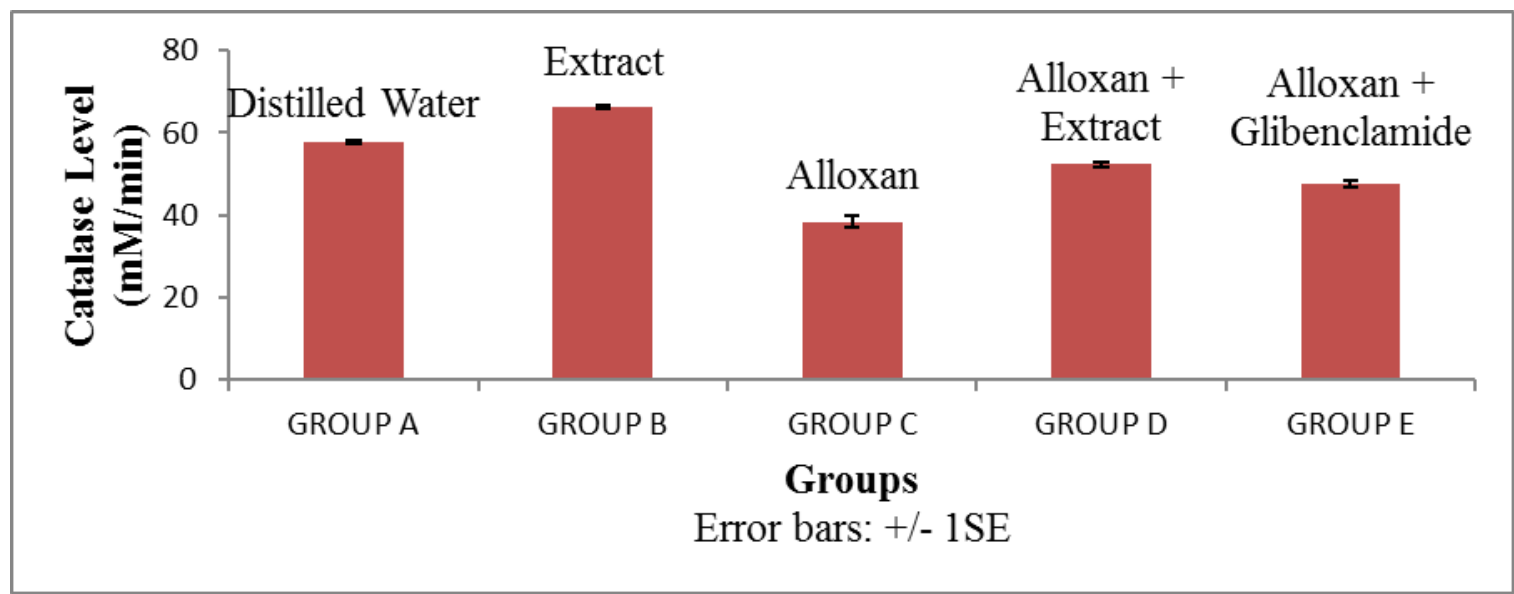

Figure 5: Effect of Eucalyptus Globulus Extract on Catalase Activity Level

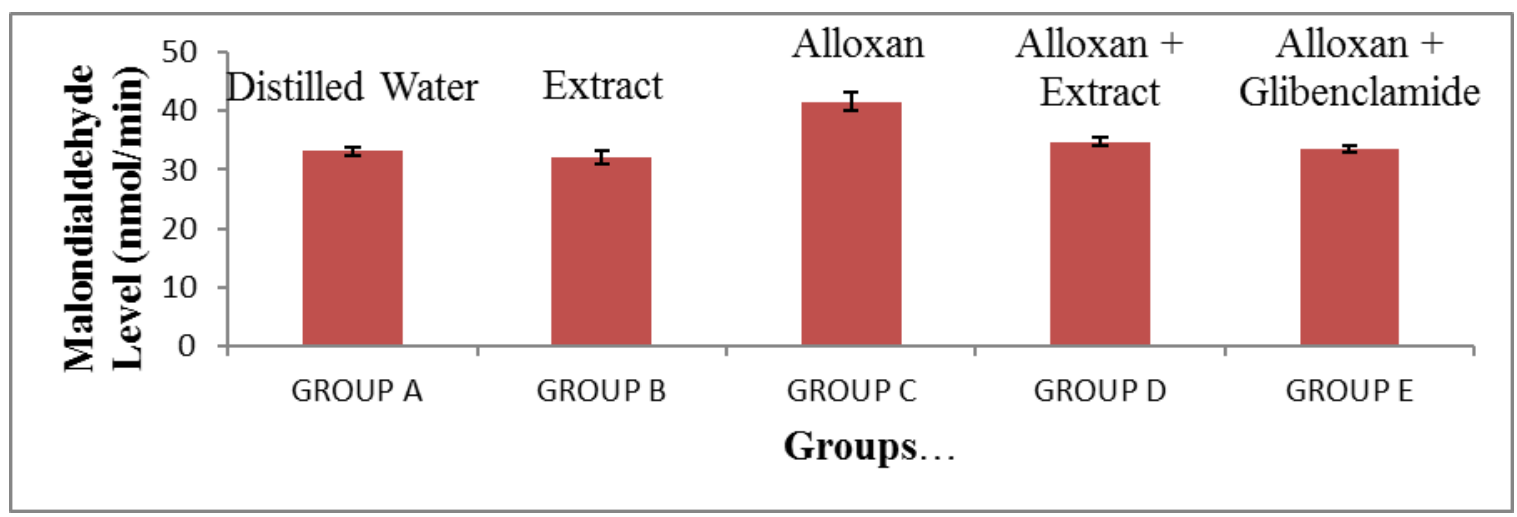

Figure 6: Effect of Eucalyptus Globulus Extract on Malondialdehyde Level

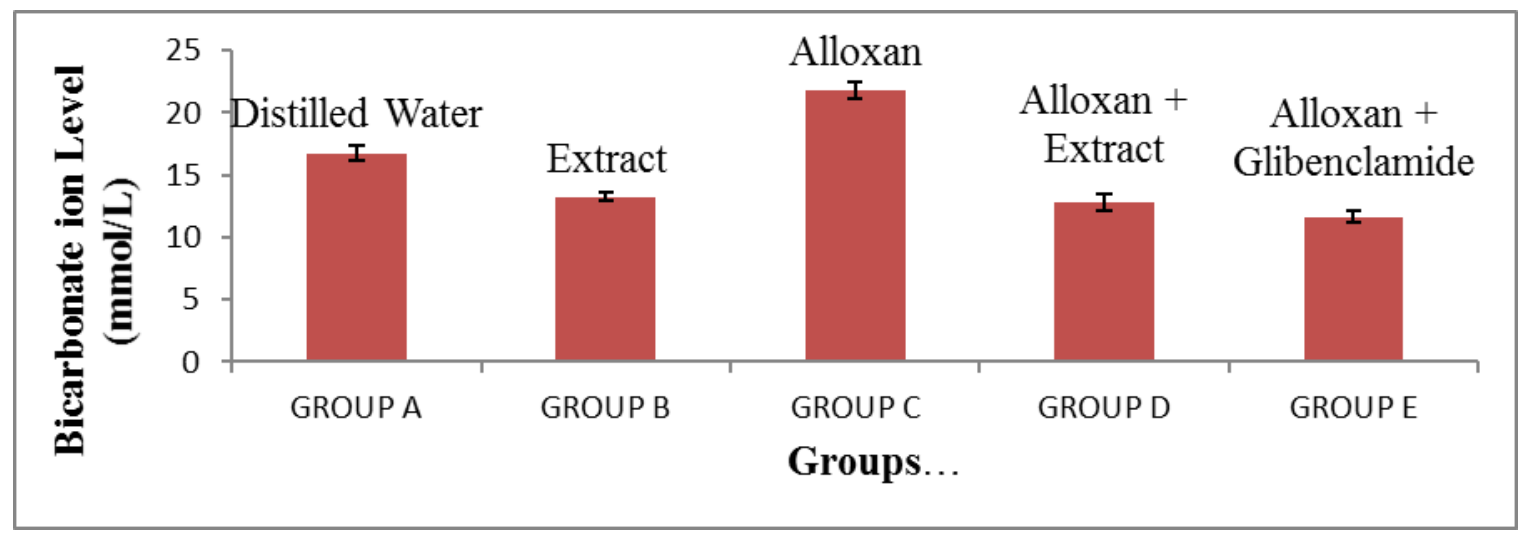

Figure 7: Effect of Eucalyptus Globulus Extract on Bicarbonate ion Level

\section{Discussion}

Aqueous extract of Eucalyptus globulus has been reported to contain eucalyptol (cineol) together with rutin, terpineol, sesquiterpene, alcohols, aliphatic aldehydes, isoamyl alcohol, ethanol, terpenes, and tanins (Duke, 1985; Eidi et al., 2009). The leaves of Eucalyptus globulus extract has also been reported to contain a high level of manganese (Pinto et al., 2007) and used in the management of diabetes with a report of high efficacy (Swanston-Flatt et al., 1990). Manganese chloride can exert a hypoglycaemic action.

However, there is little information on the effects of this botanical on diabetes-induced oxidative stress. The result of this study showed that Eucalyptus globulus has antidiabetic, hepatoprotective and antioxidative effect. The extract of Eucalyptus globulus leaves significantly reduced blood glucose. From the study, the extract produced a more 
significant fall in blood glucose level when compared with the reference drug, glibenclamide. The possible mechanism of the extract in the reduction of blood glucose could be attributed to the high concentration of manganese which modulates insulin secretion and/or insulin action (Gray and Flatt, 1998). .

The extract caused significant decline in the levels of alanine aminotranferase and aspartate aminotransaminase. This hepatoprotective effect was more significant compared to that produced by glibenclamide. The extract also reduced the level of these hepatic enzymes in diabetic condition. Serum aspartate aminotransferase (AST) or glutamic oxaloacetic transaminase (SGOT) and alanine aminotransferase (ALT) or glutamic pyruvic transaminase (SGPT) are useful biomarkers of hepatic damage (Johnson and David, 1999; knopowski et al., 2002). More importantly, raised levels of AST are often not specific for hepatic injury because it is a cardiac marker (Nyblom et al., 2004).

The extract produced a significant increase in xanthine oxidase level of the Group B animals when compared to Group A and Group C. The result of this work agrees with previous work which also has shown the significant increase in the activity of SOD (superoxide dismutase) at a dose of $100 \mathrm{mg} / \mathrm{kg}$ and it is possibly due to generation of free radical of the extract which enhances the activity of SOD to scavenge the free radicals (Pinto et al., 2007). In Group D, the extract led to significant rise in xanthine level when compared to Group C animals. There was a more significant increase in the xanthine oxidase level of the Group E animals (administered glibenclamide) when compared to xanthine oxidase level of Group D (administered extract).

The result of this study also showed that the extract Eucalyptus globulus significantly increased the catalase level of Group B and Group D when compared to Group C. Previous work had also shown that zinc, iron, manganese plays significant role in SOD (superoxide dismutase) activity as cofactors for SOD isoenzymes (Kunikowska and Jenner, 2002). Oxidative stress in diabetes coexists with a reduction in the antioxidant power (Seghrouchi et al., 2002). This study revealed similar findings with significant decline in hepatic antioxidant in diabetic rat, while E. globulus significantly enhanced the hepatic antioxidants.

The extract Eucalyptus globulus furthermore produced a non-significant reduction $(p>0.05)$ in MDA level of Group B and Group D when compared to the Group C animals. Several studies have also been shown that some constituents isolated from Eucalyptus globulus significantly reduces free radicals and inhibited lipid peroxidation (Vigo et al., 2004).

There was a significant reduction $(p<0.05)$ in $\mathrm{HCO}_{3}{ }^{-}$level of Group B and Group D animals administered with the extract when compared to Group A and Group C animals. Administration of the aqueous extract at dose $150 \mathrm{mg} / \mathrm{kg}$ to Group D and Group B animals produced the same significant effect in the lowering of bicarbonate ion $\left(\mathrm{HCO}_{3}\right)$ when compared to glibenclamide.

\section{Conclusion}

The results obtained in this study confirmed the antidiabetic potential of Eucalyptus globulus. The extract was also observed to have antioxidative, and hepatoprotective. The phytochemicals present in the extract may possibly be responsible for these effects. We however recommend further studies at the cellular and molecular levels to determine the mechanism of action of this botanical.

Declaration: Authors declare that there is no conflict of interest.

\section{References}

1. Akhigbe R.E. (2014). Discordant Results in Plant Toxicity Studies in Africa: Attempt of Standardization. In: Toxicological Survey of African Medicinal Plants. Edited by Victor Kuete. Elsevier, USA. Pp 53-61.

2. Akin M, Aktumsek A, Nostro A (2010). Antibacterial activity and composition of the essential oils of Eucalyptus camaldulensisDehn. and Myrtus communis L. growing in Northern Cyprus. African Journal of Biotechnology 9 (4): 531-535.

3. Ajayi AF, Akhigbe RE (2012). Implication of altered thyroid state on liver function. Thyroid Res Pract 9:84-7

4. 4. Arise RO, Malomo SO, Adebayo JO and Igunnu A (2009) Effects of aqueous extract of Eucalyptus globulus on lipid peroxidation and selected enzymes of rat liver. Journal of Medicinal Plants Research, 3: 077- 081.

5. Berlett SS, Stadtman ER.(1997). Protein oxidation in aging, disease, and oxidative stress. Journal of Biological Chemistry 272: 20313-20316.

6. Bremness L; (2004). Herbs. Dorling Kindersley, London. pp 54.

7. Buchbauer.G. (2000). Perfumer and flavourist,.25; 64-67.

8. Chalchat JC,Kundakovic T, Gomnovic M.S (2001). Essential Oil from the Leaves of Eucalyptus camaldulensis Dehn., Myrtaceae from Jerusalem. Journal of Essential Oil Research 13(2):105-107

9. Damjanović-Vratnica B, Đakov T, Šuković D, Damjanović J (2011). Antimicrobial effect of essential oil isolated from Eucalyptus globules Labill. from Montenegro. Czech Journal of Food Science, 29 (3): 277-284.

10. Duke JH (1985) CRC Handbook of medical herbs. CRC Press, Boca Raton, Florida, p.550. 
11. Eidi A, Eidi M, Givianrad MH, Abaspour N (2009). Hypolipidemic effects of alcoholic extract of Eucalyptus (Eucalyptus globulusLabill) leaves on diabetic and non-diabetic rats. Iran J Diab Lipid Dis 8:105-112.

12. Emara S, Shalaby AE (2011). Seasonal variation of fixed and volatile oil percentage of four Eucalyptus spp. related to lamina anatomy. Afr J Plant Sci 5(6): 353-9.

13. Finkel T, Holbrook NJ.(2000). Oxidants, oxidative stress and the biology of ageing. Nature 408: $239-247$.

14. Gray AM, Flatt PR. (1998). Antihyperglycaemicaction of Eucalyptus globules (eucalyptus) and associated with pancreatic and extrapancreatic effect in mice. J of Nutr., 128:12, 2319-2323.

15. Hamblin PS, Topliss DJ, Chosich N (1989). Deaths associated with diabetic ketoacidosis and hyperosmolar coma. Med J Australia 151:439-444.

16. Ige S.F, Akhigbe R.E, Edeogho O, Ajao F.O, Owolabi O.Q, Oyekunle O.S, Ajayi A.F, (2011). Hepatoprotective activities of Allium cepa in cadmium-treated rats. Int J Pharm Pharm Sci 3(5): 60-63

17. Ismail SM (2007). The effect of aqueous extract of leaves of Eucalyptus globules on blood Glucose level in fasted rats. Iranian Journal of Pharmacology and Therapeutics 6(2):185-186

18. Johnson and David (1999). Special considerations in interpreting liver function tests. American family physician 59 (8): 2223-2230.

19. Martin GM, Austad SN, Johnson TE. (1996). Genetic analysis of aging: Role of oxidative damage and environmental stresses. Nature Genetics 13: 25-34.

20. Knopowski J, Wieczorowska-Tobis K, Witowski J (2002). Pathophysiology of aging. Journal of Physiology and Pharmacology, 53 (2): 135-146.

21. Nyblom H, Berggren U, Balldin J, Olsson R (2004). High AST/ALT ratio may indicate advanced alcoholic liver disease rather heavy drinking. Alcohol Alcohol. 39 (4): 336-339.

22. Pietta PG.(2000). 'Flavonoids as antioxidants'Journal of Natural Products 63: 1035-1042.

23. Pinto G, Coutinho J, Araujo C, Neves L, Santos C (2007).Importance of media mineral composition on the induction of somatic embryogenesis in Eucalyptus globulus labill. Boletin de CIDEU 3:83-90.

24. Risérus U, Willet W (2009). "Dietary fats and prevention of type 2 diabetes".Progress in Lipid Research48 (1): $44-$ 51.

25. Saka W.A, Akhigbe R.E, Ishola O.S, Ashamu E.A, Olayemi O.T and Adeleke G.E, (2011). Hepatotherapeutic Effect of Aloe Vera in Alcohol-induced Hepatic Damage. Pak. J. Biol. Sci. 14: 742-746

26. Seghrouchi I, Dari J, Banner E, Riviere J, Calmard P, Garcia I, Orgiazzi J, Revol A. (2002). Oxidative stress parameters in type 1, type 2, and insulin treated type 2 diabetes mellitus; insulin treatment efficacy. ClinChimActa; 321:89-96

27. Shoback, David G. Gardner, Dolores (2011). Greenspan's basic \& clinical endocrinology (9th ed.). New York: McGraw-Hill Medical. pp. Chapter 17.

28. Swanston-Flatt SK, Day C, Balley CJ, Flatt PR (1990).Traditional plant treatment for diabetes. Studies in normal and streptozotocin diabetes mice.Diabetolozia 33:462-464

29. Vigo E, Cepeda A, Gualillo O, Perez-Fernandez R. (2004) Invitroanti inflammatory effect of Eucalyptus globulus and Thymus vulgaris: nitric oxide inhibition in J774A.1 murine macrophages. J Pharm Pharmacol; 56:257-263. 